\title{
Los testimonios de Marte en la Meseta Meridional
}

\author{
Julián Hurtado Aguña *
}

\begin{abstract}
RESUMEN SUMMARY
Marte, fue una de las más importantes divinidades romanas presentes en Hispania. Dentro de la Meseta meridional sus testimonios aparecen en algunas localidades de la provincia de Madrid, como Alcalá de Henares, Talamanca del Jarama - Collado Villalba, estando ausentes en otras partes de esta región. Especialmente importante es la presencia de inscripciones

dedicadas a Marte en la ciudad romana de Complutum (Alcalá de Henares), donde sus dedicantes

One of the most important roman divinities in Hispania was Mars. His testimonies in the Meridional Plateau are in some villages of Madrid's province, as Alcalá de Henares, Talamanca del Jarama or Collado Villalba, and they are not in other places of this region. Specially important is the presence of inscriptions to Mars in the roman town of Complutum (Alcalá de Henares), where his devotes could belong to the social freedmans group.
\end{abstract} pudieran pertenecer en algún caso al grupo social de los libertos.

Una vez que Roma controla el territorio de la península lbérica se va a producir en el ámbito religioso una coexistencia de las divinidades indígenas y romanas presentes en Hispania. Este proceso de sincretismo entre las creencias romanas e indígenas se desarrollará a lo largo de la época republicana y altoimperial. Entre las diversas dividinades del

* Universidad de Salamanca. 
panteón romano, Marte ocupaba un lugar preferente, junto a dioses como Júpiter o Mercurio, y en este sentido será una de las divinidades que recibirá mayor apoyo oficial y promoción por parte de los emperadores. Marte era una divinidad de la guerra entre cuyas primitivas advocaciones contaba también la de ser un dios protector de la fecundidad de los campos. En este sentido tenemos conocimientos que en la Roma primitiva se inmolaban caballos al dios guerrero Marte, protector de la agricultura y de la ganadería ${ }^{1}$. Esta antigua divinidad itálica formaba en Roma una triada arcaica junto a Júpiter y Quirino. Se encargaba de su culto el Flamen Martialis y también contaba con un colegio religioso, cuyos miembros eran los Salios o sacerdotes de este dios, cuya función principal consistía en organizar rituales en honor de esta divinidad. De otra parte Marte presenta dentro de Hispania un número mayor de testimonios en la provincia Tarraconense ${ }^{2}$, siendo varones la mayor parte de sus dedicantes. A nivel general, la manifestación del culto a Marte se produce en la Península en las zonas menos romanizadas. Marte después de Júpiter es la divinidad romana que recibe más culto en Hispania, si tenemos en cuenta los testimonios epigráficos que se han hallado de esta divnidad ${ }^{3}$. Entre sus devotos destaca el grupo de los militares del ejército romano (miles, centuriones, praefecti, etc.) que le dedican inscripciones en diversos lugares de Hispania ${ }^{4}$. También tenemos conocimiento de la existencia en Sagundo de un colegio de Salii o sacerdotes vinculados con el culto a Marte, faltándonos otros testimonios en la Penísula. Este hecho pudiera indicar una prerrogativa especial del culto de este dios en esta ciudad levantina. Sabemos que estos sacerdotes de Marte en Sagunto, tenían un superior que era el magister Saliorum, que normalmente era un ex duoviro ${ }^{5}$. Diversos autores clásicos también nos informan de la existencia de un dios indígena entre los celtas asimilado al Marte romano por sus características afines ${ }^{6}$. En este

Polibio 12,4. Esta práctica ritural la tenemos también documentada en otros pueblos que habitaban la Galica o el norte de la Península lbérica.

2 VÁzQuez HoYs, A. M. «La religión romana en Hispania. Análisis estadístico ll». Hispania Antiqua, 1979-1980, vol. IX-X, pág. 59.

3 Oria Segura, M. «Distribución del culto a Hércules en Hispania según los testimonios epigráficos». Habis, 20, 1989, pág. 265.

4 Se han hallado testimonios a Marte dedicados por militares en las localidades de Espino (Orense) Hep 2, 1990, 567; Añavieja (Soria) ller 251, Nivatia (Baena, Jaén) C.I.L.II 3337, y en un lugar determinado de Gallaecia C.I.L.Il 2600

5 Curchin, L. A. España romana. Conquista y asimilación. Madrid 1991, pág. 217.

6 Strabon III,3,7; Macrobio Satur 1,9,5; Silio Itálico IV,201, etc. 
sentido conocemos diversos testimonios de este Marte que aparece con epíteto indígena y están atestiguados en la región noroeste peninsular. Estos epítetos indígenas de Marte como Cosus, Coru, Caturo, Neto, etc., parecen referirse al carácter guerrero de este dios. Esta divinidad romana aparece también documentada en diversas inscripciones procedentes de la Meseta meridional. Así una inscripción votiva hallada en la localidad madrileña de Talamanca del Jarama ${ }^{7}$ está dedicada a Marte sagrado por Caburius Lupus. La inscripción presenta el siguiente texto:

\section{MARTI / SACRVM / CABVRIVS / LVPVS / V(otum) · S(olvit) $\cdot$ L(ibens) - $M($ erito $)$}

En este caso Marte va acompañado del epíteto sacrum, una fórmula que es poco frecuente dentro de la epigrafía hispana. Esta lápida está dedicada a Marte por un individuo indígena. En este caso se da la coexistencia de un antropónimo indígena y otro latino en la onomástica que presenta este individuo. En relación con el nombre indígena $\mathrm{Ca}$. burius podemos señalar que conocemos también el testimonio de la gentilidad Caburiqum documentada en Ávila que presenta el mismo radical ${ }^{8}$. El cognomen romano Lupus que menciona el epígrafe se documenta también en la Meseta meridional en otra inscripción procedente de Alhambra (C. Real) ${ }^{9}$. Kajanto nos indica que este cognomen tiene su origen entre aquellos procedentes de nombres de animales y aparece frecuentemente atestiguado en C.I.L.II. ${ }^{10}$. Alföldy sugiere para la tercera linea de esta inscripción la lectura $C$ (aius) - Aburius ${ }^{11}$ después de un estudio detallado del epígrafe y en base a una mayor presencia del nomen Aburius en la epigrafia latina peninsular. La fórmula de dedicación final (v.s.I.m.) es muy común dentro de la epigrafia votiva. La inscripción se fecha a fines del siglo I o inicios del II d.C.

Otra inscripción votiva, actualmente desaparecida, que procedia de Alcalá de Henares (Madrid) ${ }^{12}$ también estaba dedicada a esta divinidad. La inscripción presenta el siguiente texto:

\section{MARTI / VOTVM SOLVIT ANIMO LIBENS}

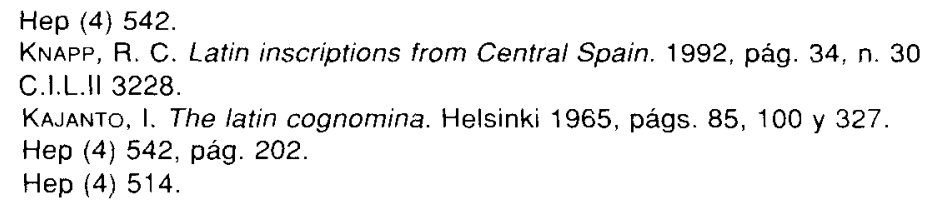


En este caso no se conserva el nombre del dedicante. El nombre de Marte aparece en esta inscripción sin un epíteto que lo acompañe. La fórmula final votum solvit animo libens es frecuente en este tipo de lápidas dedicadas a divinidades y nos indica el cumplimiento de un voto o promesa hecho con anterioridad.

También procede de la ciudad de Complutum una inscripción votiva dedicada a Marte Augusto por Appuleius Polydeuces ${ }^{13}$. Esta inscripción presenta el siguiente texto:

[M]ART[i] / AJVG(usto) SA[crum / A]PPVLE[ius / PJOLYDE[U]CES V. / S.L.M.

En este caso el nombre de Marte va acompañado del epíteto Augustus, que viene a expresar no sólo la relación emperador-divinidad, en un mismo nivel, sino también la protección que se espera de esa divinidad para con el emperador ${ }^{14}$. En la península lbérica están documentados 13 testimonios epigráficos dedicados a Marte Augusto ${ }^{15}$. El nomen romano Apuleius se documenta en otra inscripición complutense con la forma similar Apuleiano ${ }^{16}$ y en una inscripción grabada en el exterior de un cuenco hispánico ${ }^{17}$, que procede también de esta ciudad. El cognomen griego Polydeuces del dedicante sólo se atestigua en la península lbérica en otra inscripción procedente de Oliva (Valencia) ${ }^{18}$. La fórmula final de dedicación (v.s.l.m.) es bastante común dentro de la epigrafia votiva.

También procede de Complutum una inscripción dedicada a Marte por Grattius Pyramus ${ }^{19}$. Esta inscripción es recogida por Hübner con el siguiente texto:

\section{MARTI / SACRVM / GRATTIVS / PYRAMVS / V.S.M}

Este individuo porta una onomástca con duo nomina y ausencia de praenomen. El nomen romano Grattius aparece también atestiguado en la Meseta Sur en otra inscripción procedente de Valeria ${ }^{20}$.También

13 ILER 219.

14 Etienne, R. Le culte imperial dans la Peninsule lbérique d'Auguste a Diocletien. París 1958, págs. 344 y ss.

15 ETIENNE, R. Op. cit., pág. 339.

16 C.I.L.II 3042 Hep (4) 1994, n. 524.

HAE 2242.

C.I.L.II 3028.

AE 1987, 666. 
en Tarraco una lápida menciona a un individuo que porta este nomen, que era originario de la ciudad de Segóbriga ${ }^{21}$. Pyramus es un cognomen de origen griego, que no se atestigua otras veces en la epigrafia complutense. La inscripción se fecha en el siglo II d.C.

Otra inscripción votiva procedente de Complutum está dedicada a Marte por Arruntius Initialis ${ }^{22}$. Esta inscripción presenta el siguiente texto:

\section{MARTI / ARRVNTIVS / INITIALIS / V.S.M}

El nomen latino Arruntius del dedicante se documenta de forma preferente en el área occidental de la Península lbérica. Este nomen aparece también en su forma femenina en otra inscripción complutense ${ }^{23}$. El cognomen latino Initialis no presenta otros paralelos en Hispania. La fórmula final $V$ (otum) S(olvit) M(erito) es frecuente dentro de la epigrafia votiva. Esta inscripción se fecha en el período flavio o en los inicios del siglo II d. C. ${ }^{24}$

Otra inscripción votiva procedente de la localidad madrileña de Collado Villalba está dedicada a Marte, por Cantaber Elguismio hijo de Lucius. La inscripción es recogida por Hübner ${ }^{25}$ con el siguiente texto:

CANTABER / ELGVISM / IO.LVCI.P / MARTI / MAGNO / V.S.A.L

En esta inscripción Marte recibe el apelativo de Magnus. Marte dentro de la epigrafía procedente de Hispania recibe también diversos apelativos en relación con su carácter guerrero (Invictus, Victor, Ultor). Esta inscripción está dedicada por un individuo que porta una onomástica indígena. El cognomen de origen étnico Cantaber abunda en Navarra, Álava y la región celtibérica ${ }^{26}$ y también aparece atestiguado fuera de la Península. Este cognomen también se documenta en la Meseta Sur en otras dos inscripciones procedentes de las localidades conquenses de Segobriga ${ }^{27}$ y Valeria ${ }^{28}$. En relación con el nombre

2) C.I.L.II 4220.

22 C.I.L.II 3027.

23 EE,9,312.

24 Abascal, J. M. y Fernandez, D. «Epigrafía complutense». Museos 3, 1984, pág. 29.

25 C.I.L.II 3061.

26 Albertos, J. L. «La onomástica personal indigena del Noroeste peninsular». Actas del III coloquio sobre lenguas y culturas paleohispánicas. Lisboa 1980, pág. 276.

27 C.I.L.II 3135.

28 C.I.L.II 3199. 
Elguismio parece que la etimiología de su radical puede estar basada en Elanus. El mismo radical aparece en otros nombres documentados en Cantabria como Elgiano, Elguanus y Elguisteri ${ }^{29}$.

Otra divinidad clásica de la guerra con Hércules aparece también documentado en diversas inscripciones procedentes de núcleos bastante romanizados de la Mesa Sur como Segobriga o Complutum. La penetración del culto a esta divinidad se realizó en la Península a través de sectores muy romanizados. Hércules es también venerado en Hispania como dios asociado a las funciones telúricas y agrícolas. A pesar de la popularidad de la que gozaba Hércules en diversas regiones peninsulares, se han documentado hasta la actualidad un mayor número de inscripciones dedicadas a otras importantes divinidades del panteón romano como Júpiter o Marte.

En conclusión podemos afirmar que el culto a Marte dentro de la Meseta meridional parece presentar una mayor concentración de sus testimonios en la ciudad de Complutum, donde han aparecido cuatro testimonios en relación con esta divinidad. La favorable ubicación de Complutum en el entramado viario romano, su prosperidad económica y la presencia de una importante población foránea, probablemente favorieron los contactos no sólo en materia económica, sino también en la rápida asimilación de las corrientes religiosas dominantes en el Imperio. Este dato se confirma no sólo por la existencia del culto imperial en Complutum, sino también con la presencia junto a Marte de otras importantes divinidades romanas (Hércules, Fortuna, Diana) en los testimonios epigráficos procedentes de esta ciudad, que se fechan en general en los siglos I y II d.C. coincidiendo con el auge de este municipio romano. Es significativa la ausencia de testimonios dedicados a Marte en otras zonas de la Meseta Sur, donde sin embargo sí se han documentado testimonios de Hércules, otra divinidad clásica de la guerra. Sólo en las localidades madrileñas de Talamanca de Jarama y Collado Villalba se han atestiguado otros dos testimonios aislados de culto a Marte. Esta divinidad recibe diversos epítetos (Magno, Sacrum) dentro de las inscripciones procedentes de la Meseta meridional y en una lápida complutense también es calificado como Augusto, lo que le vincula con el culto imperial. En relación con los devotos de esta di-

29 IGLESIAS, J. M. Epigrafia cántabra. Estereometria, decoración, onomástica. Diputación provincial de Santander 1976, pág. 176. 
vinidad dentro de los testimonios epigráficos procedentes de esta región, podemos constatar que son varones en su totalidad y que aparecen mencionados en las inscripciones con dos elementos onomásticos bien latinos o indígenas, si bien los epígrafes no nos aportan ninguna información acerca de su status o condición social. La ausencia de praenomen entre los dedicantes pudiera indicar que no eran individuos totalmente romanizados. Este hecho se constata también si tenemos en cuenta que en las inscripciones dedicadas a Marte en esta región, no aparecen tampoco la filiación, ni la mención de tribu. Es probable que entre los dedicantes de Marte en las inscripciones complutenses se encontraran algunos libertos cuya onomástica se caracteriza en este período por la presencia de cognomina griegos. Finalmente también es significativa la ausencia de dedicantes de esta divinidad pertenecientes al estamento militar, algo frecuente en otras zonas de la Península.

\section{BIBLIOGRAFIA}

Abascal, J. M. (1994): Los nombres personales en las inscripciones latinas de Hispania. Murcia

ABASCAL, J. M. y ESPINOSA, U. (1989): La ciudad hispanorromana, privilegio y poder. Logroño. Abascal, J. M. y FennándeZ, D. (1984): “Epigrafía complutense». Museos 3, pp. 7-36.

ALTHEIM, F. (1955): La religión romaine antique. París.

BAYET, J. (1984): La religión romana. Historia política y psicológica. Madrid.

BEAUJEU, J. (1976): “Le paganisme romain sous le Haut Empire». ANRW II, 1, pp. 3-26.

BLAZQUEZ, J. M. (1962): «Religiones primitivas de Hispania. Fuentes literarias y epigráficas. Madrid.

- (1975): Diccionario de religiones prerromanas. Madrid.

- (1996): «Religiones indígenas en la Hispania romana (addenda et corrigenda)». Gerión 14, pp. 333-362.

BlAzQuEZ, J. M. y GARCIA, M. P. (1988): «Nuevas aportaciones a las religiones primitivas de Hispania". Espacio, Tiempo y Forma, UNED, pp. 153-183, Madrid.

BOYANCE, P. (1972): Etudes sur la religion romaine. Roma.

BuRgaletA, F. J. (1989): «Algunas cuestiones sobre la introducción de los cultos romanos en la Península Ibérica en época republicana". Studia Histórica, H.a Antigua, vol. VII, pp. 119-129.

CASTILLO, C.: «El progreso de la epigrafía romana en Hispania (1983-1987)». Emerita 59,2, pp. 225-273.

CUMONT, F. (1966): Recherches sur le symbolisme funeraire des romains. París.

CuRchin, L. A. (1991): España romana. Conquista y Asimilación. Edit. Gredos, Madrid.

DE LA VEGA, M. (2000): “La religión romana en la Meseta Sur: El culto a Júpiter en la provincia de Toledo a través de la epigrafía”. Conimbriga XXXIX, pp. 85-105.

DUMÉZIL, $G$. (1966): La religión romaine archaique. París.

ERCARnaÇAO, J. D. (1979): Sociedades romana e epigrafía. Setúbal, Museu de Arqueología e Etnografía.

- (1988): «Divinidades indigenas peninsulares: problemas metodológicos do seu estudo". Estudios sobre la Tabula Siarensis, CSIC, pp. 261-276, Madrid. 
ESPEJO, C. (2000): «Reflexiones sobre cultos indígenas y religión romana en el sur peninsular: Cuestiones metodológicas". Gerión, 18, pp. 213-233.

Etienne, R. (1974): Le culte imperial dans la Peninsule lberique d'Auguste a Diocletien. París.

FIScHWICK, D. (1987): The imperial cult in the latin West. Studies in the Ruler Cult of the Wester provinces of the Roman Empire. Leiden.

Garcia y BelLido, A. (1967): Les religions orientales dans le Péninsule Ibérique, Ledien.

Garcia Quintela, M. V. (1999): Mitología y mitos de la Hispania Prerromana III. Madrid.

GRIMAL, P. (1965): Diccionario de mitología griega y romana. Barcelona.

Iglesias, J. M. (1976): Epigrafía cántabra. Esterometria, decoración, onomástica. Diputación de Santander.

- (1993): «Las fórmulas en las inscripciones latinas votivas de la Hispania romana: ensayo lógico estadístico». H. ${ }^{a}$ Antigua XVII, 1993, pp. 279-320.

KNAPP, R. C. (1992): Latin Inscriptions from Central Spain.

KaJANTO, I. (1965): The latin cognomina. Helsinki.

Lane Fox, R. (1987): Pagans and Christians. Nueva York.

LAMBRECHTS, P. (1942): Contributions a l'etude des divinites celtiques. Brugge.

LoPez, G. (1989): “Avance sobre el culto a Marte indígena en la Península lbérica". Gerión, Anejos II, pp. 326-332, Madrid.

LOWIE, R. H. (1976): Religiones primitivas. Madrid.

MANGAS, J. (1971): Esclavos y libertos en la España romana. Salamanca.

MARCo SIMÓN, F. (1994): “La religión indígena en la Hispania indoeuropea" en Historia de las religiones de la Europa antigua. $\mathrm{Pp}$. 313-400.

- (1999): “Divinidades indígenas en la Hispania indoeuropea». Veleia 16, pp. 33-49.

Montenegro, A. et alii (1986): Historia de España. España romana. Editorias Gredos. Madrid.

MONTERO, S. (1982): “Marte y las arae gramineae». Archivo Español de Arqueología 55, pp. 31-34.

Olivares, J. C. (1999): «Dioses indígenas vinculados a núcleos de población en la Hispania romana". Espacio, Tiempo y Forma, pp. 325-350.

Oria Segura, M. (1989): "Distribución del culto a Hércules en Hispania según los testimonios epigráficos". Habis 20, pp. 263-273.

RODRiguez CORTÉs, J. (1991): Sociedad y religión clásica en la Bética romana. Salamanca. - (1991): "Los seviros augustales y las divinidades romanas en la Bética". Florentia lliberritana, 2, pp. 435-441.

SAGREDO, L. y JIMÉNEZ, A.: "La religión practicada por los militares del ejército romanao de Hispania durante el Alto Imperio romano (s. I-III)». Espacio, Tiempo y Forma, $\mathrm{H}^{\text {a }}$ Antigua, t. 9, pp. 289-319

SHALK, G. (1964): Leyendas de los dioses y de los héroes romanos. Barcelona.

Solana, J. M. y HeRNÁNDEZ, L. (2000): Religión y sociedad en época romana en la Meseta Septentrional. Universidad de Valladolid.

SOlOVERA, M. E. y GaRABITO, T. (1978): "La religión indigena y romana en la Rioja de los Berones". Hispania Antiqua, vol. VIII, pp. 143-199.

VAZQUEZ HoYs, A. M. (1979-1980): "La religión romana en Hispania. Análisis estadístico II». Hispania Antiqua, vol. IX-X, pp. 57-125.

- (1982): La religión romana en Hispania: fuentes epigráficas, arqueológicas y numismáticas. Madrid. 